\title{
A Modified Assay System for Collagen Glucosyltransferase
}

\author{
K. E. Draeger and K. U. Weithmann \\ Hoechst AG, Frankfurt/Main, FRG
}

Summary. A simplified assay procedure has been developed for the determination of collagen glucosyltransferase activity in tissue extracts. Using degraded gelatine as acceptor it was possible to isolate the reaction product by precipitation on to a glass fibre disc. Under our conditions degraded gelatine is glucosylated with a reaction rate which is $3-4$ times lower compared with the glucosylation of basement membrane derived glycopeptides. Good reproducibility is demonstrated by the coefficient of variation of $4 \%$ in the same assay and an interassay variation coefficient below $8 \%$. As the assay allows the testing of large numbers of samples in a few hours, it should prove a useful tool to determine the enzyme level in the tissue of diabetic animals. In humans the activity of the glucosyltransferase could provide a biochemical parameter related to diabetic microangiopathy.

Key words: Glucosyltransferase assay, rat kidney, diabetic microangiopathy, collagen, glycoproteins.

Long standing diabetes results in biochemical and morphological alterations in the capillary system of all organs so far studied. Spiro and Spiro [1] find in the kidney cortices of diabetic rats an increase of an enzyme which is involved in the posttranslational modification of BM-collagen, namely the UDP ${ }^{1}$-Glucose: Galactosylhydroxylysine-Glucosyltransferase (E. C. 2.4.1.66). Other authors [2] [3] have ques-

\footnotetext{
1 Abbreviations

UDP = uridine diphosphate

glc-gal-hyl = glucosyl-galactosyl-hydroxylysine

$\mathrm{BM} \quad=$ basement membrane
}

tioned these findings. Therefore further investigations are necessary to clarify this question. Assuming that an increased glucosylation of BM-collagen is related to $\mathrm{BM}$-thickening, the determination of glucosyltransferase activities in human tissue or blood could provide a valuable diagnostic tool to follow the pathological changes in diabetic microangiopathy.

In most of the earlier studies a tedious and time consuming assay for the glucosyltransferase was used. The purpose of our study was to modify the assay system to avoid complicated manipulations and to achieve good reproducibility.

\section{Methods}

\section{Kidney Extractions}

The glucosyltransferase was extracted from the kidneys of male albino rats of the strain Hoe: WISKf (SPF 71) (Wistar), which were fed a normal diet ad libitum prior to sacrifice.

After extirpation the kidneys were frozen in liquid nitrogen and stored in liquid nitrogen up to several months without any change in enzyme activity.

All steps were carried out at $0^{\circ} \mathrm{C}$. Kidneys were homogenized in a glass Potter homogenizer with a teflon pestle in 3.5 volumes of $0.15 \mathrm{~mol} / \mathrm{l}$ tris acetate, $\mathrm{pH} 6.8$, containing $0.002 \mathrm{~mol} / \mathrm{l} 2$ 2-mercaptoethanol and $0.25 \mathrm{ml} / 100 \mathrm{ml}$ Triton X 100 . After stirring for one hour the homogenate was centrifuged at $100000 \times \mathrm{g}$ for one hour.

To the supernatant polyethyleneglycol 6000 was added to a final concentration of $7 \%(\mathrm{w} / \mathrm{v})$. After stirring for $15 \mathrm{~min}$ the suspension was centrifuged at $30000 \mathrm{x}$ f for $20 \mathrm{~min}$. The precipitate was redissolved in the above mentioned buffer. The enzyme solutions were stored at $-20^{\circ} \mathrm{C}$; no change of enzyme activity was observed under those conditions within two months.

\section{Enzyme Assay}

In our modified assay the glucosyltransferase was determined using degraded gelatine as the acceptor. The reaction product was isolated in a disc precipitation procedure similar to that of Mans 


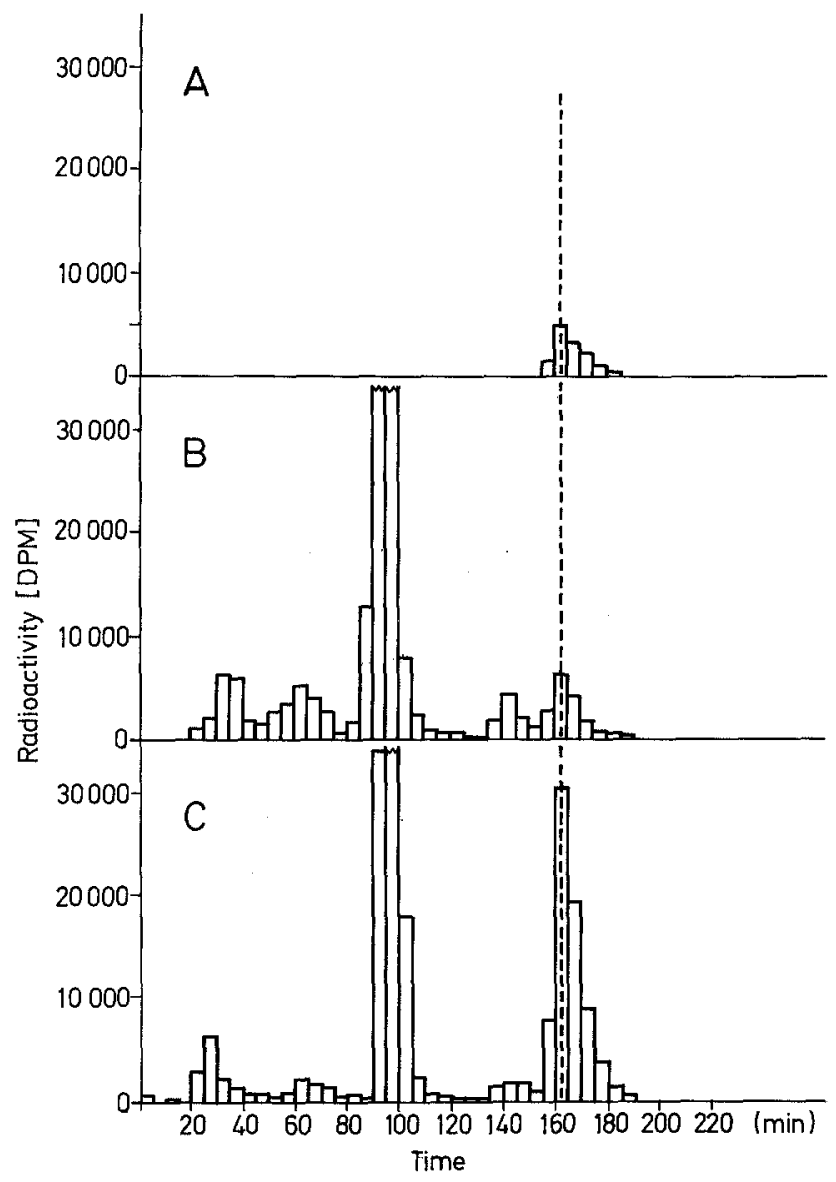

Fig. 1. Amino acid analysis of the glucosyltransferase reaction product after alkaline hydrolysis. The broken line indicates the position of glc-gal-hyl. $\mathbf{A}=$ degraded gelatine (precipitate); $\mathbf{B}=$ degraded gelatine (incubation mixture) $\mathbf{C}=$ basement membrane peptide (incubation mixture)

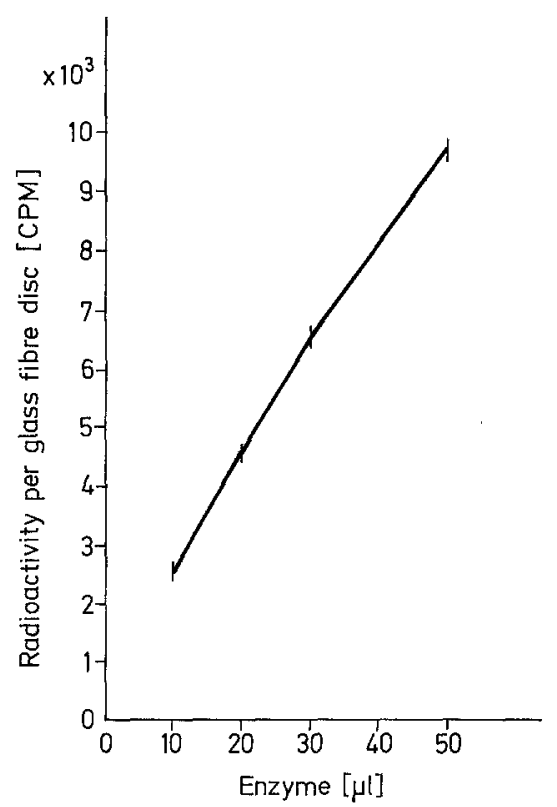

Fig. 2. Effect of enzyme concentration on the incorporation of glucose- ${ }^{14} \mathrm{C}$ into degraded gelatine $(n=5$, mean $\pm S E M)$ and Novelli [4]. The incubations were carried out at $37^{\circ} \mathrm{C}$ in a total volume of $0.15 \mathrm{ml}$, containing $22.5 \mu \mathrm{mol}$ tris acetate, $\mathrm{pH} 6.5,3.0$ $\mu \mathrm{mol}$ manganese acetate, $0.3 \mu \mathrm{mol} 2$-mercaptoethanol, $22.5 \mu \mathrm{mol}$ sodium chloride and $6 \mathrm{mg}$ partially degraded gelatine with a content of $5 \mathrm{nmol}$ non-glucosylated galactosyl residues per $\mathrm{mg}, 5$ residues hydroxylysine per 1000 amino acids and a molecular weight of 10-15000 (Behringwerke AG, Marburg). The assay system for glucosyltransferase contained $10 \mathrm{nmol}$ of UDP-glucose${ }^{14} \mathrm{C}(0.76 \mu \mathrm{Ci})$ (Radiochemical Centre, Amersham). The reaction was started by adding 5 to $50 \mu l$ of the enzyme solution and stopped after $40 \mathrm{~min}$ by transferring an $100 \mu \mathrm{l}$ aliquot of the reaction mixture on to a glass fibre disc (Whatman GF/C, $2.3 \mathrm{cms}$ size). The disc was brought to near dryness by a stream of warm air and then immersed in a solution of $1 \%(\mathrm{w} / \mathrm{v})$ phosphotungstic acid in $0.5 \mathrm{~mol} / 1 \mathrm{HCl}$ for 15 minutes. Finally it was washed successively for $15 \mathrm{~min}$ each: four times in $1 \mathrm{~mol} / \mathrm{l}$ trichloracetic acid, twice in ether/ethanol $(1: 1, \mathrm{v} / \mathrm{v})$ and once in ether. After drying the disc was transferred to a toluene scintillation solution and counted. To characterize the reaction product some of the discs were subjected to alkaline hydrolysis and analyzed as described later.

For comparative purposes the enzyme was tested for activity by the method of Spiro et al. [5], using glycopeptide from bovine glomerular basement membrane as acceptor. Following alkaline hydrolysis the C-14-labelled degradation product glc-gal-hyl was isolated by paper chromatography or by means of an automated amino acid analyzer.

Amino acid analysis was carried out following hydrolysis in $2 \mathrm{~mol} / 1 \mathrm{NaOH}$ at $105^{\circ} \mathrm{C}$ in capped polypropylene tubes for $20 \mathrm{hr}$. The hydrolysates were acidified, desalted on columns of Dowex 50 WX8, according to Spiro [5], and analyzed on a Beckman Multichrom 4255 automated amino acid analyzer. The effluent was fractionated and radioactivity determined in a liquid scintillation counter. Automatic external standardization as well as internal standards were used for determining counting efficiencies. Protein was determined by the method of Lowry et al. [6] using bovine serum albumin as a standard.

\section{Results}

In order to facilitate the test procedure for the glucosyltransferase we looked for a suitable acceptor which is precipitable under conditions where the cosubstrate UDP-glucose remains in solution. We checked the glycopeptide fraction derived from glomerular basement membrane [5], under-glucosylated collagen (where glucose was partly removed by an acid hydrolysis under mild conditions), and degraded gelatine. To achieve a rapid and specific separation, the labelled reaction product was precipitated on a glass fibre disc. The most effective precipitant was phosphotungstic acid [7], and subsequent washes with trichloroacetic acid, ethanol and ether. Under these conditions the best substrate with respect to availability, handling properties, quantitative and specific precipitation, was degraded gelatine. As shown by amino acid analysis the only C-14labelled product in the hydrolysate of the precipitate was the glc-gal-hyl residue (Fig. $1 \mathrm{~A}$ ). When the incubation mixture including the excess of UDP-glucose was subjected to alkaline hydrolysis, peaks not corresponding to glc-gal-hyl were seen and glc-gal-hyl 
represented a minute portion of the radioactive components in the hydrolysates (about $1 \%$ of the total radioactivity) (Fig. 1B). A similar pattern in the amino acid analysis was obtained when the substrate was BM-glycopeptide and the alkaline hydrolysis was carried out according to [5] (Fig. 1C).

Figure 2 shows the effect of enzyme concentration on the incorporation of C-14-glucose into degraded gelatine. In the same assay four enzyme concentrations were determined five times. Under these conditions good reproducibility is demonstrated by the coefficient of variation of $4 \%$.

In two enzyme solutions glucosyltransferase activity was determined six times each within a period of two months. The interassay coefficients of variation in these series, representing high (mean $597 \mathrm{cpm} / \mathrm{mg}$ kidney) and low (mean $459 \mathrm{cpm} / \mathrm{mg}$ kidney) enzyme activities were $7.4 \%$ and $7.5 \%$ respectively. The reaction rate with degraded gelatine in our assay is $7 \mathrm{pmol} / \mathrm{mg}$ min, which is $3-4$ times lower than the rate of glucosylation of $\mathrm{BM}$ glycopeptides determined according to [5]. Double reciprocal plots of initial velocity and substrate concentrations were linear. The $\mathrm{K}_{\mathrm{m}}$ obtained for UDPglucose was about $70 \mu \mathrm{mol} / \mathrm{l}$ and that for gelatine about $22 \mathrm{~g} / 1$ (Fig. 3).

The activity of kidney glucosyltransferase shows a marked variation with age [8] with highest values in animals of about nine days of age. Table 1 shows that values are stable in adult rats of two different weights and also gives the normal range for our strain of rats.

\section{Discussion}

Spiro's method for the determination of glucosyltransferase activities [5] includes several tedious and time consuming steps: the preparation of the substrate from glomerular basement membrane and the steps following the enzyme reaction involving alkaline hydrolysis, ion exchange chromatography and a paper chromatographic technique taking six days. The test procedure of Myllylä [9], using gelatinized calf skin collagen as acceptor, includes a precipitation step, alkaline hydrolysis, ion exchange chromatography and paper electrophoresis.

These manipulations which are necessary to achieve a high specificity of the test imply many potential sources of error. Both authors claim that several purification steps are necessary because the separation efficiency of one step is not sufficient.

We think that the intensive purification procedures are mainly necessary to eliminate labelled products derived from the UDP-glucoside, which were removed either incompletely or not at all before

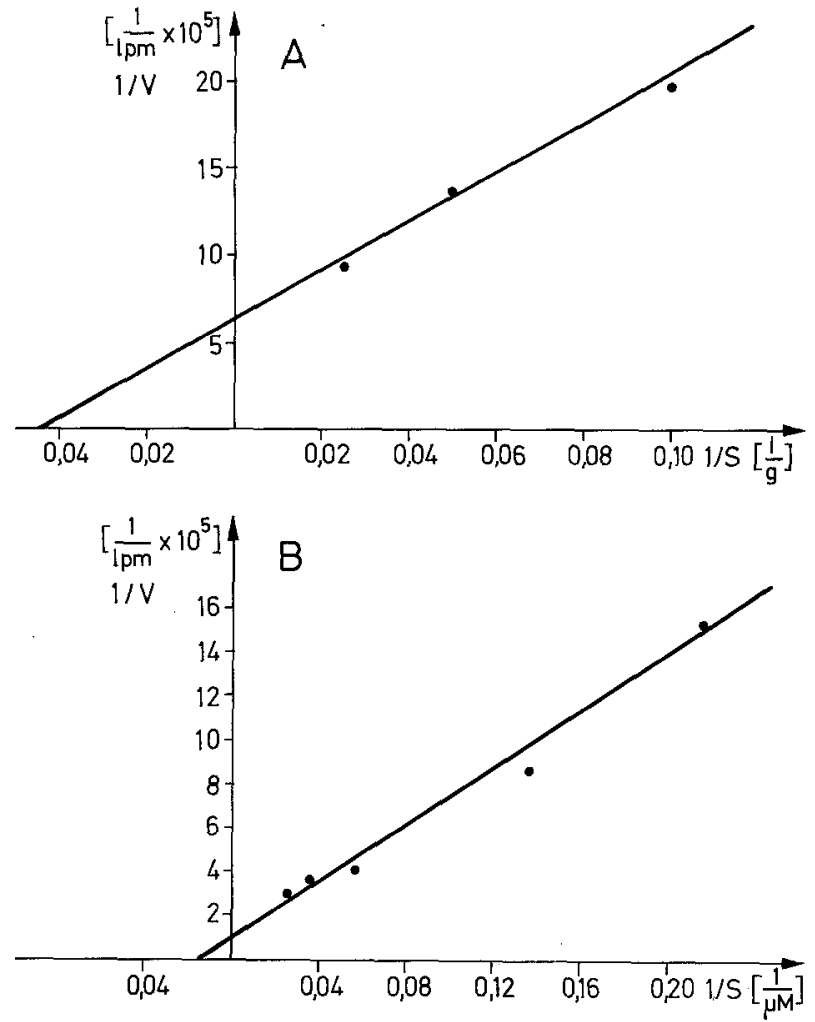

Fig. 3. Lineweaver-Burk plot for glucosyltransferase with degraded gelatine $\mathbf{A}$ and UDP-glucose $\mathbf{B}$ as the variable substrates. Standard assay conditions were employed with substrate concentrations as indicated and $0.27 \mathrm{mg}$ enzyme protein

Table 1

\begin{tabular}{|c|c|c|c|c|}
\hline 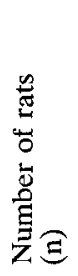 & 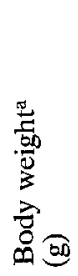 & 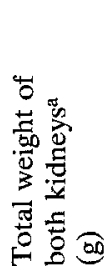 & 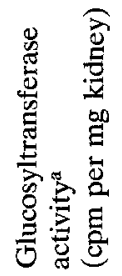 & 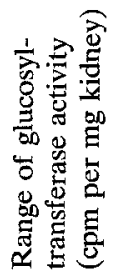 \\
\hline 15 & $\begin{array}{r}372 \\
\pm 11\end{array}$ & $\begin{array}{r}2,2 \\
\pm 0,1\end{array}$ & $\begin{array}{r}524 \\
\pm 27\end{array}$ & $440-580$ \\
\hline 20 & $\begin{array}{r}497 \\
\pm \quad 9\end{array}$ & $\begin{array}{r}2,8 \\
\pm 0,1\end{array}$ & $\begin{array}{r}517 \\
\pm 46\end{array}$ & $423-675$ \\
\hline
\end{tabular}

a The values are given as the mean \pm SEM

alkaline hydrolysis. We used a commercially available degraded gelatine, with a molecular weight of $10-15000$, as acceptor. After quantitative precipitation on a glass fibre disc the excess of labelled UDPglucose was washed out completely. When this precipitate was subjected to alkaline hydrolysis the only labelled product found in the hydrolysate was glcgal-hyl, as shown by amino acid analysis. Obviously there is no need for any further processing of the precipitate to achieve a high specifity of the assay. 
The reaction rate with degraded gelatine as an acceptor is lower than with BM-glycopeptides. This is probably due to the specificity of the enzyme and to the lower content of acceptor sites in the degraded gelatine and does not conflict with the requirements for such an assay.

The main asset of this procedure is that it allows the testing of large numbers of samples in a few hours, using special devices for the washing steps.

Acknowledgements. We are indebted to Dr. H. H. Schöne for performing the amino acid analyses and helpful discussions and wish to thank Miss G. Kaule and Mrs. C. Steinert for their excellent and skilful assistance.

\section{References}

1. Spiro, R. G., Spiro, M. J.: Effect of diabetes on the biosynthesis of the renal glomerular basement membrane, studies on the glucosyltransferase. Diabetes 20, 641-648 (1971)

2. Risteli, J., Koivisto, V. A., Åkerblom, H. K., Kivirikko, K. J.: Intracellular enzymes of collagen biosynthesis in rat kidney in streptozotocin diabetes. Diabetes 25, 1066-1070 (1976)

3. Duhault, J., Lonchampt, M.: Glucosyl transferase activity and diabetic microangiopathy. Biomedicine 27, 127-131 (1977)

4. Mans, R. J., Novelli, G. D.: Measurement of the incorporation of radioactive amino acids into protein by a filter-paper disc method. Arch. Biochem. Biophys. 94, 48-53 (1961)
5. Spiro, R. G., Spiro, M. J.: Studies on the biosynthesis of the hydroxylysine-linked disaccharide unit of basement membranes and collagens. I. Kidney glucosyltransferase. J. Biol. Chem. 246, 4899-4909 (1971)

6. Lowry, O. H., Rosebrough, N. J., Farr, A. L., Randall, R. J.: Protein measurement with the folin phenol reagent. J. Biol. Chem. 193, 265-275 (1951)

7. Kirschbaum, B. B., Bosmann, H. B.: The interaction of folic acid and glycoprotein glycosyltransferase activities of rat kidney. Biochim. Biophys. Acta 320, 416-426 (1973)

8. Spiro, R. G., Spiro, M. J.: Studies on the biosynthesis of the hydroxylysine-linked disaccharide unit of basement membranes and collagens. III. Tissue and subcellular distribution of glycosyltransferases and the effect of various conditions on the enzyme levels. J. Biol. Chem. 246, 4919-4925 (1971)

9. Myllylä, R., Risteli, L., Kivirikko, K. J.: Assay of collagengalactosyltransferase and collagen-glucosyltransferase activities and preliminary characterization of enzymic reactions with transferase from chick-embryo cartilage. Eur. J. Biochem. 52, $401-410$ (1975)

Received: February 14, 1977,

and in revised form: March 7, 1978

Dr. K. E. Draeger

Hoechst AG

Pharma Biochemie H 821

Postfach 800320

D-6230 Frankfurt/Main 80

Federal Republic of Germany 